\title{
Honey and Medicinal Plants in the Management of Certain Surgical Bovine Clow Affections
}

\begin{abstract}
Owing to the worldwide spread of bacterial antimicrobial resistance, it is of great concern to search for antimicrobial agents of natural origin. Since the antimicrobial activity of honey was widely documented, the study aimed to evaluate its use comparing with certain medicinal plants extracts as surgical dressing of bovine clow affections. Aqueous extracts of Thymus vulgaris (T. vulgaris), Matricaria chamomilla (M. chamomilla) and Origanum vulgare (O. vulgare) were prepared to be used in vitro and in vivo studies in this work. Clinical aerobic or anaerobic bacterial strains were isolated from some clinical surgical bovine clow affections, and were used to determine the minimal inhibitory concentrations (MICs) of the prepared extracts against these pathogens.The study concluded that all tested aerobic bacterial strains were inhibited with $10 \%$ of all tested extracts, while the anaerobic strains were inhibited with $10 \%$ of T. vulgaris and $15 \%$ of both $O$. vulgare and M. chamomilla extracts. According the achieved MICs values, lotions and ointments of the entended medicinal plants were made to be used during the in vivo study as follow: 20 lactating dairy cows suffering from different surgical clow affections were classified to equal four groups (A -D) which were managed with surgical dressing and received: honey (A): T. vulgaris (B), M. chamomilla: (C) and $O$. vulgare: (D) extracts with their MICs. All cows of groups A \& $\mathrm{B}(\mathrm{no}=10)$ as well as one cow from group $(\mathrm{C})$ showed complete healing by the day 30 while, none of group (D).The study concluded that with the alternative medical trends, application of honey - as it is - in surgical dressing of bovine digital dermatitis or inter digital necrobacillosis is the most effective valuable economic tool among the four materials studied for its superurity and feasibility followed by the use of T. vulgaris extract $10 \%$ in lotion and ointment preparation.
\end{abstract}

Keywords: Honey; Thymus vulgaris; Origanum vulgare; Matricaria chamomilla; digital dermatitis and interdigital necrobacillosis

\author{
Research Article \\ Volume 9 Issue 3 - 2017 \\ Ali MA' ${ }^{1}$, Saleh $\mathrm{AS}^{1}$, Abdul-Hafeez $\mathrm{MM}^{2 *}$ and \\ Koreim $\mathbf{A M}^{2}$ \\ ${ }^{1}$ Department of surgery, Assiut University, Egypt \\ ${ }^{2}$ Department of surgery, Assiut University, Egypt \\ *Corresponding author: Abdul-Hafeez MM, Animal \\ Health Research Institute, Faculty of veterinary medicine, \\ Department of surgery, Assiut University, Egypt, \\ Email: lab.moh_hafeez55@yahoo.com
}

Received: April 03, 2017 | Published: November 20, 2017

\section{Introduction}

By the increase worldwide spread of multidrug resistant pathogens rather than the public health hazard of antibiotic residues in bovine milk and meat; searching for antimicrobial agents other than antibiotic becomes an issue of great interest. Moreover; the ability of bacteria to develop biofilm-associated drug resistance have further increased the number of life threatening bacterial infections in humans ${ }^{1}$. Honey has recently received attention as a complementary and alternative treatment in modern medicine [2]; and there is attention its use as a topical therapeutic agent for wound infection and becomes part of conventional medicine for wound care [3] since; it promotes healing process [4]; it contains antibacterial compounds against multidrug-resistant bacterial infections [5] rather than; prevention biofilm formation; and decrease production of bacterial virulence factors [6].

Essential oils (EOs) extracted from medicinal plants are considered attractive natural antimicrobial agents.T. vulgaris is a medicinal plant which its EO -with the main component thymolis active against Salmonella; Staphylococcus [7-9]; Streptococcus mutans and Lactobacillus species [10]. T.vulgaris essential oils are widely used in food preservation mainly meat industry as its antibacterialagents [11]. M. chamomilla flower extract contain potential sources of antimicrobial nano molecules and with antimicrobial activities [12] mainly; against $S$. aureus; E. coli [13] and C. albicans [5] and reduces bacterial biofilm accumelation [14]. When; it was used as wound dressing loaded with $15 \%$ chamomile extract were remarkably capable to heal $(99 \pm 0.5 \%)$ after 14 days post-treatment periods [15]. O. vulgaris EO is effective against Salmonella enterica; S. mutans; molds and yeasts; and mesophilic aerobic bacteria [7]; Escherichia coli; Clostridium perfringens; and Salmonella [16] where carvacrol and thymol are the major components responsible for the antimicrobial effects of O. vulgaris EO [17]. O. vulgaris EO has also antifungal activity with minimal fungicidal concentrations $0.05 \% \mathrm{v} / \mathrm{v}$ [18]. The present work aimed to evaluate the use of honey comparing with some medicinal plant extracts in management of certain bovine clow affections.

\section{Material and Methods}

\section{Medicinal plant extracts}

T. vulgaris leaves; 0 . vulgare leaves and $M$. chamomilla flowers let to be dried in open air. Each dried plant was soaked in freshly boiled distilled water for 24 hours to collect plant aqueous

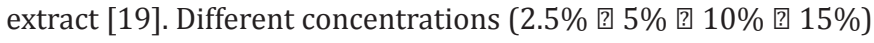


of each herbal extract were prepared to be standard extract concentrations(SE conc.) used during the work either in vitro or in vivo procedures.

\section{Bacterial strains}

From clinical bovine clow affections (sole ulcer; interdigital dermatitis; interdigital necrobacillosis and digital dermatitis); clinical bacterial strains were isolated as follows; the clows were washed and cleansed to remove mud and manure using sterile distilled water.Gentle curetting of lesion edges with a disinfected curette; then samples were taken aseptically from the affected areas using sterile bacteriological swabs soaked in sterile modified transport broth. Each sample was divided into two brain heart infusion broth tubes.The first portion was incubated aerobically for $24 \mathrm{~h}$ to isolate and identificate aerobic bacterial contents [20]. The second was incubated anaerobically for $48 \mathrm{~h}$. for isolation and identification [21].

\section{MIC determination}

MIC of medicinal plant extracts was done to perform the effective solutions and ointments used during the study.The different obtained SE concentrations were used instead of distalled water to prepare blood agar with $10 \%$ of citrated sheep blood [20] and fusobacterium egg yolk agar plates [21]. The isolated aerobic strains were streaked onto blood agar and incubated at 37 ? for $24 \mathrm{~h}$ while the anaerobic isolates were sreaked onto fusobacterium egg yolk agar at 37 ? for $48 \mathrm{~h}$.

\section{Preperation of herbal ointments}

applicable ointment was achieved by adding the obtained SE conc.as herbal MIC to meltedpetroleum jelly [19].

\section{Tested animals}

20 lactating dairy Holstein cows in a dairy farm at Assiut government aging $4-6$ years old weighing about $400-450 \mathrm{gk}$. body weight. Cows were suffering lameness with active lesions (digital dermatitis and interdigital necrobacillosis). Animals were maintained under the same management; housing conditions and were fed the same ration. They were randomly devided to four equal groups of 5 cows (group A; B; C and D); where :

a. was managed with honey as it is.

b. was managed with MIC lotion and ointment of T. vulgaris.

c. was managed with MIC lotion and ointment M. chamomilla.

d. was managed with MIC lotion and ointment $O$. vulgare.

Cows were managed surgically as: application protocol required to wash and cleansed the lesion with a low-pressure water hose.Group (A) treated by honey; after washing and cleaning the lesion; the honey was applied topically; then protected by means of bandage. For other groups(B; C and D); by using calibrated sprayer bottles for spraying the MIC lotions; then the ointment applied topically and protected by means of bandage.On day $(0)$; prior to any treatment; all cows were evaluated for pain; lameness and lesion dimention scores. All cows were treated once daily for
5 consecutive days; 2 days without management; then treated once daily for other 3 days only up to 14 adys. Cows were manged twice weekly for other two weeks. Cows were re-examined on days 14 and 30 for pain; lameness; and lesion scores [22].

\section{Results}

In vitro study: extracts of T. vulgaris leaves (B); O. vulgare leaves (C) and M. chamomilla (D) flowers containing their active principles were tested against the isolated bacterial strains with

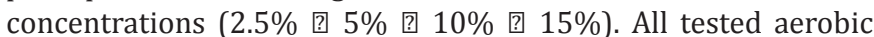
bacterial strains were inhibited with MICs values $10 \%$ of all extracts; while anaerobic ones were inhibited with $10 \%$ of $T$. vulgaris and $15 \%$ of both 0 . vulgare and M. chamomilla (Table 1). About the in vivo work: according the obtained tested extract MICs; lotion and ointment of T. vulgaris were prepared of $10 \%$; but for M. chamomilla and $O$. vulgare were that of $15 \%$ (Table 1 ). All cows (no $=20$ ) in the four tested groups -before any interferenceshowed ( severe degree of pain and lameness where the lesion dimensions $\emptyset$ were above $2 \mathrm{~cm}$ ). Table 2 showed all testing score on day $14 \& 30$; where by the day 30 ; all managed cows constituted both groups $A \& B($ no $=10)$ and only one cow belonged to group $C$ showed complete healing with pain and lameness relieved as well as healthy skin (table 2 and fig 1;2;3); while none of group D cured or healed completely (Table 2 \& Figure 4).

Table 1: The minimal inhibitory concentration (MIC) of medicinal plant extracts for the isolated micro organisms from clinical cases.

\begin{tabular}{|c|c|c|c|c|}
\hline \multicolumn{2}{|c|}{ Isolated Micro-Organisms } & B & C & D \\
\hline \multirow{3}{*}{ Aerobic } & Staph aureus & \multirow{3}{*}{\multicolumn{3}{|c|}{$10 \%$}} \\
\hline & Strept pyogenes & & & \\
\hline & Corynebacterium pyogenes & & & \\
\hline \multirow{4}{*}{ Anaerobic } & Fusobacterium necrophorum & \multirow{4}{*}{$10 \%$} & \multirow{4}{*}{\multicolumn{2}{|c|}{$15 \%$}} \\
\hline & Bacteroides nodosus & & & \\
\hline & Peptostreptococcus anaerobs & & & \\
\hline & Clostridium sp. & & & \\
\hline
\end{tabular}

B: T. vulgaris; C: M. chamomilla; D: O. vulgare extracts.

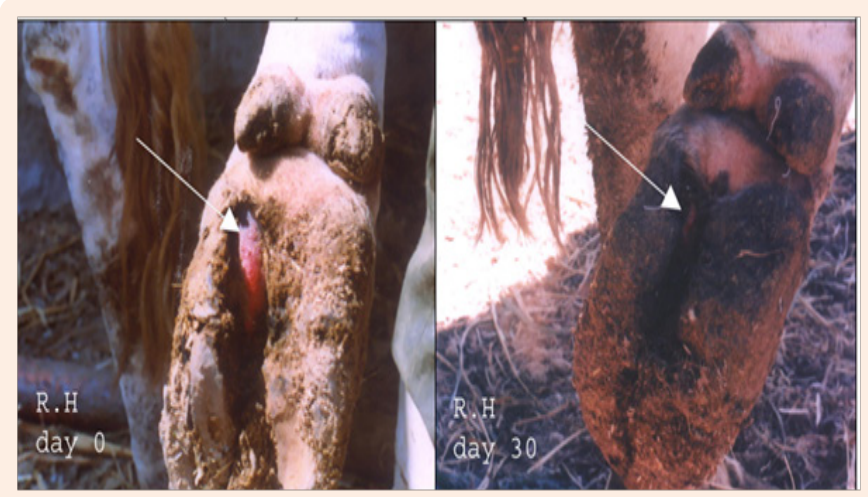

Figure 1: Planter aspect of right hind limb showing digital dermatitis of medial claw (arrows) before and after honey treatment. 
Table 2: Different treatment managements with medicinal plant extracts and surgical curing scores along the full experimental course.

\begin{tabular}{|c|c|c|c|c|c|c|c|c|c|c|c|c|c|c|}
\hline \multicolumn{4}{|c|}{ Day 30} & \multicolumn{4}{|c|}{ Day 14} & \multicolumn{4}{|c|}{ Day 0} & \multirow{2}{*}{$\begin{array}{l}\text { No. of Cows in } \\
\text { Each Group }\end{array}$} & \multirow{2}{*}{\multicolumn{2}{|c|}{ Testing Score }} \\
\hline D & $\mathrm{C}$ & B & A & D & C & B & A & D & C & B & A & & & \\
\hline 2 & 1 & - & - & 2 & 1 & - & - & 5 & 5 & 5 & 5 & \multirow{10}{*}{5} & Severe & \multirow{3}{*}{ Pain } \\
\hline 3 & 3 & - & - & 3 & 4 & 4 & 3 & - & - & - & - & & Mild & \\
\hline- & 1 & 5 & 5 & - & - & 1 & 2 & - & - & - & - & & Pain relived & \\
\hline 3 & 1 & - & - & 5 & - & - & - & 5 & 5 & 5 & 5 & & $\begin{array}{c}\text { Initial wound } \varnothing \text { was more } \\
\text { than } 2.5 \mathrm{~cm}\end{array}$ & \multirow{3}{*}{$\begin{array}{c}\text { Lesion } \\
\text { dimensions } \varnothing\end{array}$} \\
\hline 2 & 4 & - & - & - & 3 & 4 & 3 & - & - & - & - & & $=2.5 \mathrm{~cm}$ & \\
\hline - & - & 5 & 5 & - & 2 & 1 & 2 & - & - & - & - & & $\begin{array}{l}\text { Final wound } \varnothing \text { was }(>2.5-0) \\
\qquad \mathrm{cm}\end{array}$ & \\
\hline 3 & - & - & - & - & - & - & - & 5 & 5 & 5 & 5 & & Severe & \multirow{4}{*}{ Lameness } \\
\hline 2 & - & - & - & 3 & 4 & 4 & 3 & - & - & - & - & & Moderate & \\
\hline- & 4 & - & - & 2 & 1 & 1 & 2 & - & - & - & - & & Mild & \\
\hline - & 1 & 5 & 5 & - & - & - & - & - & - & - & - & & Lameness relived & \\
\hline
\end{tabular}

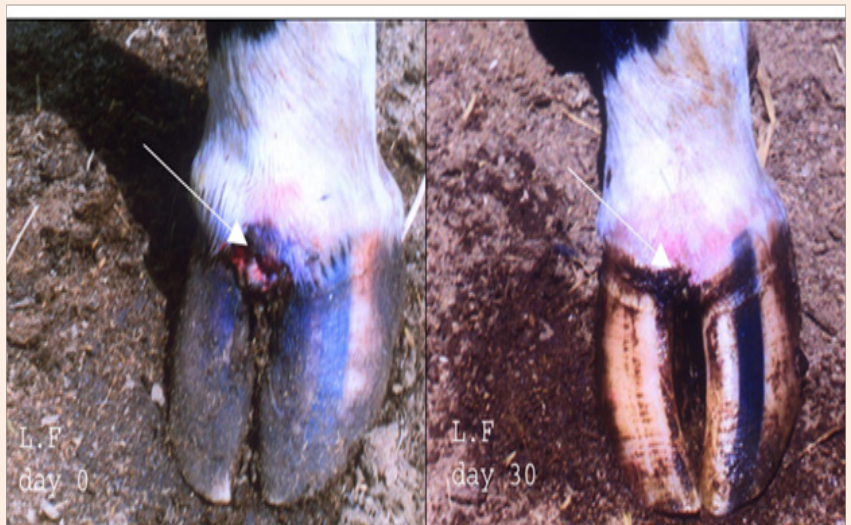

Figure 2: Dorsal aspect of left fore limb showing interdigital necrobacillosis (arrows) before and after Thymus vulgaris extract treatment.

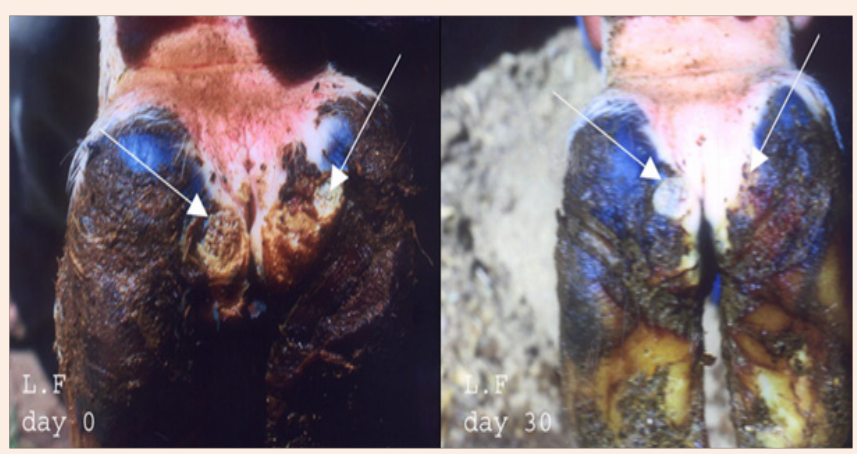

Figure 3: Palmer aspect of left fore limb showing digital dermatitis of medial and lateral claws (arrows) before and after Matricaria chamomilla extract treatment.

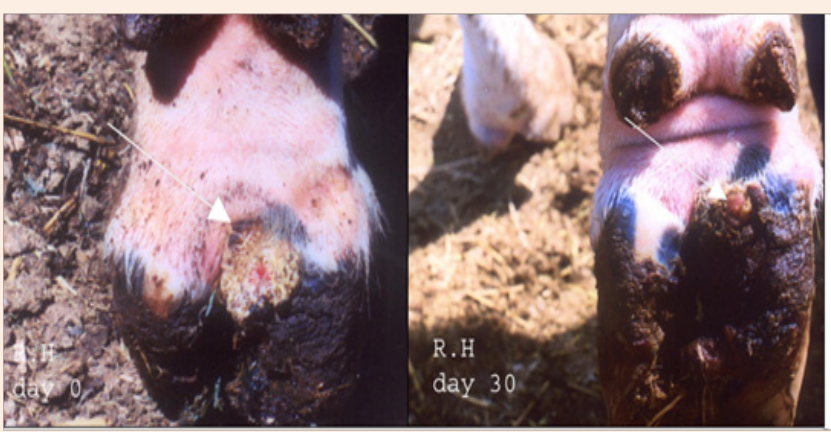

Figure 4: Planter aspect of right hind limb showing digital dermatitis of lateral claw (arrows) before and after Origanum vulgare extract treatment.

\section{Discussion}

Honey dressing is increasingly being used for wound infections with great success because of its multiple benefits over conventional therapy. Thus is due to its antibacterial activity ${ }^{5}$ either by the high osmotic pressure; low $\mathrm{pH}$ acidic environment; low protein content; high carbon to nitrogen ratio; other chemical agents phytochemicals [23]; by the direct action of liberated $\mathrm{H}_{2} \mathrm{O}_{2}{ }^{4}$; by the synergistic antioxidant compounds flavenoid and polyphenols [24] or combination of these factors according the floral nectar [24]\}. Moreover; in vivo application it was a favorable for its healing promoting effects [25] and its immuno-modulating action[26,27] especially; honey - with proliferation of both B \& T lymphocytes - does not help in the growth of yeast and bacteria[23]; rather than its great economic impact. Honey was tested in vitro against aerobic bacteria such as; S. aureus [28]; MRSA[29-31]; E. coli [32]; S. typhimurium [33]; Klebsiella pneumonia [34]; Ps. Aerugenosa ${ }^{35}$ and anaerobic Porphyromonas gingivalis [36]. Also its antifungal activity against Candida sp. [37] or Leptospermum scoparium [38] is documented. 
According to its in vivo studies; honey topical application is recommended in difficult surgical wounds such as burns [39]; chronic leg wounds [25]; venous leg ulcers [40] or diabetic foot lesions [41]. Carnwath et al (2014) tested in vitro the antimicrobial activity of different honey batches against 10 different bacterial species concluding that it may be effective topical treatment up to 16 concentration. Tramuta et al; (2017) recommended manuka honey or honeydew to form honey based membrane as a topical application for wound dressing in veterinary clinical medicine. So; the study aimed to evaluate its use comparing with certain medicinal plants extracts as surgical dressing of bovine clow affections judging by the clinical parametrs (pain testing; lamness and wound contractin dimentions).

In the present study; with the terminal end of the experiment (day 30); both honey and T. vulgaris resulted in complete healing process. But honey use was more preferable as cows treated with honey relieved the initial testing scores by the day 14 earlier than those treated with T. vulgaris. So; honey is recommended for its superiority as well as its use feasibility since it is used as it is in the dressing instead of lotion and ointment. Honey through different studies has almost equal or slightly superior effects when compared with conventional treatments for acute wounds [34] especially pan- or multidrug-resistant bacterial infections [5]. Consequently; honey is getting worldwide attention as a topical therapeutic agent for wound infection and potential future candidate for systemic infections [42].

Thyme essential oil has a significant bacteriostatic activity against the microorganisms ${ }^{9 ; 10}$ which is more pronounced against the Gram's +ve bacteria [12]; so it is widely used in food preservation mainly meat industry as its antibacterial agents [11]. M. chamomilla flower extract containing potential sources of antimicrobial nano molecules [43] and reduces biofilm accumulation with $1 \%$ [14]. M. chamomilla antimicrobial activity is conflicting issue since; good activity was recorded through wound dressing samples loaded with $15 \%$ extract were remarkably capable to heal the wounds up to $99 \pm 0.5 \%$ after 14 days post-treatment periods [15]. On the other hand; during a study [44] the authors examined the antibacterial effect of several medicinal plants E. oils against 3 Gram's +ve and 3 Gram's -ve concluded no bacterial inhibition activity for M. chamomilla against all tested bacterial species. Another study stated that among 7 tested medicinal plant E. oils; M. chamomilla showed the least antibacterial effect against the tested bacterial sp [44]. Although; $O$. vulgaris extract exhibit good bactericidal; antibiofilm activity [17] and rich in small terpenoids and phenolic compounds; which are known to have antimicrobial activities [7]; rather than another study [18] estimated their antifungal activity in very low concentrations (less than $0.05 \%$ ); it resulted delayed healing and persistence of testing scores (pain; lameness and wide wound) in all cows of group (D) during the present study with the least positive effects to be unfavorable not recommendable treatment.

\section{Conclusion}

The study concluded that with the alternative medical trends: application of honey - as it is - in surgical dressing of bovine digital dermatitis or interdigital necrobacillosis is the most effective valuable economic tool among the four materials studied for its superiority and feasibility followed by the use of T. vulgaris extract $10 \%$ in lotion and ointment preparation.

\section{Acknowledgment}

None.

\section{Conflict of Interest}

None.

\section{References}

1. Swamy MK, Akhtar MS, Sinniah UR (2016) Antimicrobial Properties of Plant Essential Oils against Human Pathogens and Their Mode of Action: An Updated Review. Evid Based Complement Alternat Med 2016: 3012462 .

2. Jull AB, Rodgers A, Walker N (2015) Honey as a topical treatment for wounds. Cochrane Database Syst Rev 4: CD005083.

3. Mogib El-Dahtory FA, Yahia S (2011) Cytoprotective effect of honey against chromosomal breakage in fanconi anemia patients in vitro. Indian J Hum Genet 17(2): 77-81.

4. Molan PC (1999) The Role of Honey in the Management of Wounds. J Wound Care 8(8): 415-418.

5. Hussain MB (2017) Role of Honey in Topical and Systemic Bacterial Infections. Journal of alternative and complementary medicine 9.

6. Maddocks SE, Jenkins RE (2013) Honey: A sweet solution to the growing problem of antimicrobial resistance? Future Microbiol 8(11): 1419-1429.

7. Kwon SJ, Chang Y, Han J (2017) Oregano essential oil-based natural antimicrobial packaging film to inactivate Salmonella enterica and yeasts/molds in the atmosphere surrounding cherry tomatoes. Food Microbiology 65: 114 - 121.

8. Soković M, Glamočlija J, Marin PD, Brkić D, van Griensven LJ (2010): Antibacterial effects of the essential oils of commonly consumed medicinal herbs using an in vitro model. Molecules 15(11): 75327546.

9. Prasanth R, Ravi V, Varsha PV, Satyam S (2014) Review on Thymus vulgaris traditional uses and pharmacological properties. Med Aromat Plants 3 (4): 1-3.

10. Tardugno $\mathrm{R}$, Pellati $\mathrm{F}$, Iseppi $\mathrm{R}$, Bondi $\mathrm{M}$, Bruzzesi $\mathrm{G}$, et al. (2017) Phytochemical composition and in vitro screening of the antimicrobial activity of essential oils on oral pathogenic bacteria. Nat Prod Res 17: 1-8.

11. Ballester-Costa C, Sendra E, Fernández-López J, Pérez-Álvarez JA, Viuda-Martos M (2017) Assessment of Antioxidant and Antibacterial Properties on Meat Homogenates of Essential Oils Obtained from Four Thymus Species Achieved from Organic Growth. Foods 6(8): pii: E59.

12. Miraj S, Alesaeidi S (2016) A systematic review study of therapeutic effects of Matricariarecuitta chamomile (chamomile) .Electron Physician 8(9): 3024-3031.

13. Dogru E, Demirbas A, Altinsoy B, Duman F, Ocsoy I (2017) Formation of Matricariachamomilla extract-incorporated Ag nanoparticles and size-dependent enhanced antimicrobial property. J PhotochemPhotobiol B 174: 78-83. 
14. Goes P, Dutra CS, Lisboa MR, Gondim DV, Leitão R, et al. (2016) Clinical efficacy of a 1\% Matricaria chamomile L. mouthwash and $0.12 \%$ chlorhexidine for gingivitis control in patients undergoing orthodontic treatment with fixed appliances. J Oral Sci 58(4): 569574.

15. Motealleh B, Zahedi P, Rezaeian I, Moghimi M, Abdolghaffari AH, et al. (2014) Morphology, drug release, antibacterial, cell proliferation, and histology studies of chamomile-loaded wound dressing mats based on electrospunnanofibrous poly(varepsilon-caprolactone)/ polystyrene blends. J Biomed Mater Res B ApplBiomater 102(5): 977-87.

16. Du E, Gan L, Li Z, Wang W, Liu D, et al. (2015) In vitro antibacterial activity of thymol and carvacrol and their effects on broiler chickens challenged with Clostridium perfringens. J Anim Sci Biotechnol 6: 58.

17. Khan ST, Khan M, Ahmad J, Wahab R, Abd-Elkader OH, et al. (2017) Thymol and carvacrol induce autolysis, stress, growth inhibition and reduce the biofilm formation by Streptococcus mutans. AMB Express $7(1): 49$.

18. Brochot A, Guilbot A, Haddioui L, Roques C (2017) Antibacterial, antifungal, and antiviral effects of three essential oil blends. Microbiologyopen 6(4).

19. Chevallier A (1996) The encyclopedia of medicinal plants. ( $1^{\text {st }}$ edn), DK publishing Inc. London, pp. 76 -295.

20. Quinn PJ, Carter ME, Markey BK, CarterGR (1994) Clinical Veterinary Microbiology. Virginia Tech, Blacksburg, USA.

21. Koneman EW, Allen DS, Jang W M, Schrechen BP, Winn WJ (1992) Colour Atlas and text book of diagnostic microbiology. 4 th $\left(4^{\text {th }} \mathrm{edn}\right)$, J.B. Lippincott Co. Phladilphia, USA.

22. Hernandez J1, Shearer JK, Elliott JB (1999) Comparison of topical application of Oxytetracycline and four nonantibiotic solutions for treatment of papillomatousdigital dermatitis in dairy cows. J Am Vet Med Assoc 214(5): 688 - 690

23. Samarghandian S, Farkhondeh T, Samini F (2017) Honey and Health: A Review of Recent Clinical Research. Pharmacognosy Res 9(2): 121127.

24. Alzahrani HA, Boukraa L, Bellik Y, Abdellah F, Bakhotmah BA, et al. (2012) Evaluation of the antioxidant activity of three varieties of honey from different botanical and geographical origins. Glob J Health Sci 4(6): 191-196.

25. Yaghoobi R, Kazerouni A, Kazerouni O (2013) Evidence for Clinical Use of Honey in Wound Healing as an Anti-bacterial, Anti-inflammatory Anti-oxidant and Anti-viral Agent: A Review. Jundishapur J Nat Pharm Prod 8 (3): 100-104.

26. Sayed SM, Abou El-Ella GA, Wahba NM, El Nisr NA, Raddad K, et al. (2009) Immune defense of rats immunized with fennel honey, propolis, and bee venom against induced staphylococcal infection. J Med Food 12(3): 569-575.

27. Hegazi A, Amr MA, Fyrouz AA (2013) Influence of Honey on Immune Response Against Newcastle Disease Vaccine. International Journal of Basic and Applied Virology 2(1): 01-05.

28. Aamer AA, Abdul-Hafeez MM, Sayed SM (2014) Minimum Inhibitory and Bactericidal Concentrations (MIC and MBC) of Honey and Bee Propolis against Multi-Drug Resistant (MDR) Staphylococcus $s p$. Isolated from Bovine Clinical Mastitis. Alternative \& Integrative Medicine AlternInteg Med 3: 4
29. Almasaudi SB, Al-Nahari AAM, Abd El-Ghany ESM, Barbour E, Al Muhayawi SM, et al. (2017) Antimicrobial effect of different types of honey on Staphylococcus aureus. Saudi J Biol Sci 24(6): 1255-1261.

30. Rani GN, Budumuru R, Bandaru NR (2017) Antimicrobial Activity of Honey with Special Reference to Methicillin Resistant Staphylococcus aureus (MRSA) and Methicillin Sensitive Staphylococcus aureus (MSSA). J ClinDiagn Res 11(8): DC05-DC08.

31. Pasupuleti VR, Sammugam L, Ramesh N, Gan SH (2017) Honey, Propolis, and Royal Jelly: A Comprehensive Review of Their Biological Actions and Health Benefits. Oxid Med Cell Longev 2017: 1259510.

32. Emineke S, Cooper AJ, Fouch S, Birch BR, Lwaleed BA (2017) Diluted honey inhibits biofilm formation: potential application in urinary catheter management? J ClinPathol F 70 (2): 140-144.

33. Ekhtelat M, Ravaji K, Parvari M (2016) Effect of Iranian Ziziphus honey on growth of some foodborne pathogens. J Nat SciBiol Med $7(1): 54-57$.

34. El-Kased RF, Amer RI, Attia D, Elmazar MM (2017) Honey-based hydrogel: In vitro and comparative In vivo evaluation for burn wound healing. Sci Rep 7(1): 9692.

35. Prateeksha, Singh BR, Shoeb M, Sharma S, Naqvi AH, et al. (2017) Scaffold of Selenium Nanovectors and Honey Phytochemicals for Inhibition of Pseudomonas aeruginosa Quorum Sensing and Biofilm Formation. Front Cell Infect Microbiol 7: 93.

36. Eick S, Schäfer G, Kwieciński J, Atrott J, Henle T, et al. (2014) Honey-a potential agent against Porphyromonas gingivalis: an in vitro study. BMC Oral Health 14: 24.

37. Firdose A, Nisar A, Dsouz, MR (2016) Evaluation of in vitro antimicrobial activity of Indian honey on burnwound isolates. Journal of Chemical and Pharmaceutical Research 8(3): 1027-1034.

38. Adams CJ, Manley-Harris M, Molan PC (2009) The origin of methylglyoxal in New Zealand manuka (Leptospermum scoparium) honey. Carbohydr Res 344(8): 1050-1053.

39. Shupp JW, Nasabzadeh TJ, Rosenthal DS, Jordan MH, Fidler P, et al. (2010) A reviews of the local pathophysiologic bases of burn wound progression. J. Burn Care Res 31(6): 849-873.

40. Gethin G, Cowman S, Kolbach DN (2015) Debridement for venous leg ulcers. Cochrane Database Syst Rev (9): CD008599.

41. Jull AB, Walker $N$ and Deshpande $S$ (2013) Honey as a topical treatment for wounds. Cochrane Database Syst Rev 2: CD005083.

42. Paramasivan S, Drilling AJ, Jardeleza C, Jervis-Bardy J, Vreugde S, et al. (2014) Methylglyoxal-augmented manuka honey as a topical antiStaphylococcus aureusbiofilm agent: safety and efficacy in an in vivo model. Int Forum Allergy Rhinol 4(3): 187-195.

43. Mekonnen A, Yitayew B, Tesema A, Taddese S (2016) In Vitro Antimicrobial Activity of Essential Oil of Thymus schimperi, Matricaria chamomilla, Eucalyptus globulus, andRosmarinu sofficinalis. Int J Microbiol 2016: 9545693.

44. Herman A (2014) Comparison of antimicrobial activity of essential oils, plant extracts and methylparaben in cosmetic emulsions: 2 months study. Indian J Microbiol 54(3): 361-364.

45. Tramuta C, Nebbia P, Robino P, Giusto G, Gandini M, et al. (2017) Antibacterial activities of Manuka and Honeydew honey-based membranes against bacteria that cause wound infections in animals. Schweiz Arch Tierheilkd 159(2): 117-121. 
46. Carnwath R, Graham EM, Reynolds K, Pollock PJ (2014) The antimicrobial activity of honey against common equine wound bacterial isolates. Vet J 199(1): 110-114. 